\title{
Indexação bibliográfica em bases de dados: O que é? Para que serve? Onde estamos?
}

\author{
Paulo Elias C. Dantas*
}

É muito freqüente a alegação de alguns importantes pesquisadores/autores brasileiros de que "não publicam o resultado de suas pesquisas nos Arquivos Brasileiros de Oftalmologia, em razão de nossa revista não ser indexada”.

Responda rapidamente, querido leitor: Você realmente sabe o que é indexação bibliográfica, o que ela significa para você e para o pesquisador brasileiro? Você sabe como obtêla? Você sabe quais são as principais bases de dados referenciais do mundo e seus critérios de seleção e inclusão? Você acha ou presume que a não inclusão de revistas nacionais nessas bases de dados é problema exclusivo dos nossos dirigentes e editores? Como diria aquela propaganda de jornal: "Está na hora de rever seus conceitos!"

Após o árduo processo de transformar os resultados de sua pesquisa em texto científico, o autor e seus colaboradores partem para outro momento de decisão crítica: onde publicar o resultado do estudo, de tal modo que seja visto, analisado e se torne acessível à comunidade científica, que dará ou não o devido mérito às eventuais descobertas e inovações que a pesquisa traz. A busca da publicação de seu trabalho em revistas indexadas por bases de dados internacionais parece ser o caminho natural, porém elas não são muitas em nossa especialidade e, dada a relação procura/demanda, muitas vezes leva-se tempo para publicá-los, além da dificuldade em vencer certas barreiras xenófobas de algumas editorias internacionais.

Uma das missões dos Arquivos Brasileiros de Oftalmologia é de dar visibilidade aos artigos publicados, divulgar e disseminar internacionalmente a produção científica nacional, além de manter seu registro (preservando sua memória), facilitando assim a sua verificação por meio de indicadores específicos de produção científica. As condições citadas nos impelem à busca de reconhecimento e indexação em bases de dados referenciais internacionais. Vale lembrar que os ABO já são indexados no LILACS (Literatura Latino-Americana e do Caribe de Informação em Ciências da Saúde) e podem ser acessados de qualquer lugar do planeta pela SciELO-Scientific Eletronic Library (www.scielo.com.br), que é uma base de dados com textos completos de revistas selecionadas, criada e mantida pela Fundação de Amparo à Pesquisa de São Paulo (FAPESP) em associação com a BIREME, e pelo ScirusScientific Information (www.scirus.com), um dos mais im-

* Editor Associado - Arquivos Brasileiros de Oftalmologia portantes mecanismos de busca de informação científica da Internet.

Então, por que buscar indexação em outras bases de dados referenciais? A resposta é aumentar o alcance de divulgação e exposição da ciência nacional. Hoje as principais bases de dados referenciais do mundo são Medline (Index Medicus), a EMBASE (Excerpta Medica) e o BIOSIS (Biological AbstractsCurrent Contents).

Na busca pela indexação, todos desempenham papel importante. Cabe ao Editor e seus Associados:

- manter a periodicidade e regularidade de publicação da revista;

- seguir convenções editoriais internacionais (para facilitar a recuperação dos artigos originais em qualquer lugar do planeta);

- submeter os artigos enviados para análise e revisão aos pares (peer review);

- dar caráter de internacionalidade à revista, globalizá-la (com publicacão de artigos científicos em outras línguas, como inglês e espanhol, e citar artigos de autores de outros países).

Como é de conhecimento de todos, os ABO são publicados ininterruptamente desde 1938, usa os principais critérios de submissão editorial sugeridos pelo International Committee of Medical Journal Editors (para texto completo e atualizado, consulte www.icmje.org), é peer reviewed e publica artigos em Português, Inglês e Espanhol. Além disso, faz intercâmbio de comunicações científicas com sociedades científicas internacionais, como a Sociedade Mexicana de Oftalmologia, publicando excertas de artigos científicos destas Sociedades.

Cabe aos autores e pesquisadores nacionais:

- Publicar artigos originais com boa metodologia científica e estatística;

- Citar artigos publicados nos ABO como referência, quando optar por publicações em revistas estrangeiras, gerando maior índice de fator de impacto para os $\mathrm{ABO}$ (quanto mais um trabalho for citado como referência, maior o impacto científico deste trabalho, e, conseqüentemente, quanto maior o número de trabalhos citados como referência publicados em uma revista científica, maior será o seu fator de impacto). Alguns indexadores só admitem indexação de revistas com fator de impacto bibliográfico relevante. Citar os ABO bibliograficamente, melhora sua qualificação junto às bases de dados internacionais na hora do processo de seleção e/ou de avaliação. 
A Editoria Científica dos ABO estabeleceu a indexação em duas bases de dados internacionais como prioridade em sua busca por excelência em 2004. Na realidade, já estamos sob processo de avaliação para indexação no BIOSIS-Current Contents/Institute for Scientific Information (ISI-Thomson), no EMBASE (Excerpta Medica) e no MedLine.

O trabalho certamente será árduo e sofrerá adequações durante o processo de inclusão nestas bases de dados referenciais. Porém, com a participação de todos, Editores, auto- res, revisores e a comunidade científica oftalmológica em geral, poderemos, num futuro não tão distante, alcançar a tão sonhada excelência da indexação.

\section{REFERÊNCIA}

1. Krzyzanowski RF. Qual o significado da indexação das publicações científicas na área da saúde? In Ecos da 16a Reunião Anual, São Paulo, 2003. Disponível na URL http://www.bireme.com.br

\title{
XL REUNIÃO DO CENTRO DE ESTUDOS OFTALMOLÓGICOS "CYRO DE REZENDE"
}

\section{2 a 04 de Dezembro de 2004 \\ Centro de Convenções de Ribeirão Preto - SP}

\author{
Departamento de Oftalmologia, Otorrinolaringologia e \\ Cirurgia de Cabeça e Pescoço da Faculdade de Medicina \\ da USP de Ribeirão Preto
}

Tema: "Superfície Ocular"

INFORMAÇÕES: Eventus Planejamento e Organização

Fone: (1 1) 3361-3056 - Fax: (1 1) 3361-3089

E-mail: oftalmo@eventus.com.br

Home-page: www.eventus.com.br/oftalmo 